\title{
Forced Expiratory Volume Decreased, CTCAE
}

National Cancer Institute

\section{Source}

National Cancer Institute. Forced Expiratory Volume Decreased, CT CAE. NCI Thesaurus.

Code C143494.

A finding based on test results that indicate a relative decrease in the fraction of the forced vital capacity that is exhaled in a specific number of seconds. 